\title{
MIDAS
}

Museus e estudos interdisciplinares

$3 \mid 2014$

Varia e dossier temático: "Museos y participación biográfica"

\section{Entroncamento de histórias: Registo de testemunhos orais}

Junction of histories: Record of oral testimonies

\section{Daniela Rodrigues do Rosário}

\section{(2) OpenEdition}

\section{Journals}

Edição electrónica

URL: http://journals.openedition.org/midas/558

DOI: $10.4000 /$ midas.558

ISSN: 2182-9543

\section{Editora:}

Alice Semedo, Paulo Simões Rodrigues, Pedro Casaleiro, Raquel Henriques da Silva, Ana Carvalho

\section{Refêrencia eletrónica}

Daniela Rodrigues do Rosário, « Entroncamento de histórias: Registo de testemunhos orais », MIDAS [Online], 3 | 2014, posto online no dia 21 maio 2014, consultado no dia 30 abril 2019. URL : http:// journals.openedition.org/midas/558; DOI : 10.4000/midas.558

\section{Este documento foi criado de forma automática no dia 30 Abril 2019}

\section{cc) (†)}

Midas is licensed under a Creative Commons Attribution-NonCommercial-ShareAlike 3.0 International License 


\title{
Entroncamento de histórias: Registo de testemunhos orais
}

\author{
Junction of histories: Record of oral testimonies
}

\author{
Daniela Rodrigues do Rosário
}

1 A história dos caminhos de ferro é muito mais do que falar em máquinas, estações de passageiros, rotundas de locomotivas, viadutos ou pontes. É feita de pessoas, dos ferroviários, das suas vivências e experiências. Histórias de vida, familiares e profissionais, que nos permitem, quando já não existe material do passado, ver aquilo que deixou de existir (Pesavento 2002).

2 O homem é um ser cultural e é o produto de uma determinada cultura, que integra uma organização social. A cultura transmite-se e cada geração vindoura recebe-a como de património se tratasse. E porque cada pessoa a pode trabalhar, acrescentar novas contribuições, estamos perante produtores de cultura. No quotidiano deste grupo socioprofissional, sujeito a uma disciplina que se revela no seu fardamento, ajustado, naturalmente, às suas funções e grau hierárquico, encontram-se as memórias de quem faz parte da história dos caminhos de ferro.

3 A memória existe, segundo Ribeiro (2003, 1), aliada ao esquecimento, sendo ambos «componentes da memória, um não existe sem o outro, no processo de atualização do passado, quando evocado. É a memória que nos dá a sensação de pertencimento e existência, daí a importância dos lugares de memória para as sociedades humanas e para os indivíduos». E é, ainda, definida por Chapouthier $(2006,9)$ como «a capacidade que certos seres vivos têm de armazenar, no sistema nervoso, dados ou informações sobre o meio que os cerca, para assim modificar o próprio comportamento.»

4 O património ferroviário é vasto, dividindo-se em móvel, imóvel e bens intangíveis. É nesta última dimensão que se encontram os hábitos, os saberes, os costumes, as tradições, bem como a memória. É a memória do homem que faz a história das gentes. É esta a base da oralidade e é através deste processo de comunicação que é possível recontar os feitos e avivar as lembranças. Desta forma, o património recorda as vivências, mantém e preserva 
a identidade de uma nação, de uma família (Choay 1992). O património é a herança que nos foi deixada pelos nossos antepassados.

É neste contexto que surge o projeto Entroncamento de histórias, organizado pelo serviço educativo do Museu Nacional Ferroviário.

O Museu Nacional Ferroviário foi criado em 1991, através de legislação, no entanto, apenas em 2005 se decidiu avançar para a execução do projeto, constituindo para esse efeito uma fundação ${ }^{1}$, à qual estivessem associadas as empresas de cariz público e privado do setor ferroviário. Assim sendo, a Fundação Museu Nacional Ferroviário Armando Ginestal Machado foi criada para responder às necessidades sentidas pelas empresas do mundo ferroviário no âmbito da recolha, preservação, estudo e divulgação do seu património histórico. Em 2007, a fundação instala-se no Entroncamento, pois a cidade apresentava características únicas, nomeadamente pela existência de antigas instalações oficinais desativadas, que foram entendidas como os espaços ideais para acolher as exposições do museu. O primeiro departamento a ser criado foi o serviço educativo. Composto por profissionais de diversas áreas, tem como principal objetivo sensibilizar os públicos de uma forma pedagógica para o património ferroviário. Através de atividades de diversos tipos pretende-se também chegar junto da comunidade local, das escolas, dos centros de dia, despertando para a importância da preservação do património ferroviário.

7 É no sentido de ir ao encontro desta população que o projeto Entroncamento de histórias se assume como essencial, pois permite preservar os testemunhos orais de antigos ferroviários, as suas vivências, as suas profissões e, assim, a partir da memória coletiva, recriar o quotidiano destes homens, pois os bens materiais por si só não o conseguem fazer. Contudo, é urgente ouvi-los, uma vez que este é um tipo de fonte que se finda no tempo.

a recurso à memória oral surge então como um complemento ao registo através de documentos. As histórias narradas oralmente vão permitir de forma coletiva recontar um determinado momento.

O primeiro Entroncamento de histórias teve lugar em 2012, no Dia Internacional dos Museus, no Salão Paroquial da Sagrada Família e contou com a presença de cerca de 190 crianças de várias escolas da cidade (João de Deus, Rumo ao Futuro e Gustavo Eiffel). Participaram também cerca de 30 séniores (Lar dos Ferroviários, Lar Fernando Eiró, Santa Casa da Misericórdia e Universidade Sénior) e funcionários do museu.

De forma a que a recolha de testemunhos fosse o mais abrangente possível, procurou-se selecionar diferentes profissões, tendo sido escolhidos 15 antigos ferroviários para contarem as suas experiências de vida.

11 As entrevistas realizaram-se de forma individual e foram conduzidas por uma técnica do serviço educativo, com base num pequeno guião, incluindo questões como o nome e a idade, a profissão e o tempo de serviço na empresa Comboios de Portugal (СP). A partir daí, os entrevistados referenciaram os momentos que consideraram mais importantes nas suas carreiras, tendo muitos deles contado as suas histórias também a partir de fotografias que levaram. As entrevistas foram gravadas em suporte vídeo.

12 Com estas conversas foi possível reunir uma vasta informação sobre o dia a dia de algumas profissões que já deixaram de existir e ainda outras que tiveram de se adaptar aos novos tempos. Maquinista, auxiliar de manutenção, operário das oficinas, guarda de passagem de nível, ferramenteiro, são alguns desses exemplos. 

Museus, desta vez nos Sabores do Mercado (antigo Centro Cultural do Entroncamento) numa sessão aberta ao público, que contou com testemunhos relativas a profissões como inspetor de circulação, fator e contramestre de mecânica dos motores diesel. Neste contexto, a metodologia seguida foi a mesma da primeira sessão.

14 foi a forma encontrada de complementar a informação de que o museu já dispunha. Para preservar e divulgar este tipo de fontes, os testemunhos constarão na exposição permanente do museu, na forma de registo físico. É neste sentido, que os museus devem ser entendidos, ou seja, como locais onde se promove e se divulgam saberes e conhecimentos; um local onde os objetos, enquanto recursos museológicos, devem ser articulados com outras fontes de informação.

O Museu Nacional Ferroviário encontra-se temporariamente encerrado ao público e está prevista a sua abertura no primeiro semestre de 2014 com uma exposição permanente e uma exposição temporária. Para o efeito, foram recuperados o antigo armazém de víveres, uma oficina do vapor e encontram-se a ser intervencionadas duas outras oficinas, bem como a rotunda de locomotivas ou redonda, nome pelo qual é conhecida na gíria ferroviária. Com as obras de requalificação e expansão, será possível expor uma grande parte da coleção que a fundação detém, recorrendo-se simultaneamente a equipamentos tecnológicos, o que tornará, certamente, o espaço mais atrativo e interativo. ${ }^{2}$

O Entroncamento de histórias veio promover uma maior abertura à comunidade local e é um projeto que terá continuidade no futuro. Sendo os testemunhos orais cruciais para a compreensão da vida ferroviária, no seu sentido mais amplo, o Museu Nacional Ferroviário, mais concretamente o serviço de inventário, vai propor que os visitantes deixem os seus conhecimentos e histórias numa Folha de Testemunho. Este será um complemento ao registo que já é efetuado aquando das doações, onde existe o cuidado de haver uma conversa com o doador, ouvindo tudo o que tem a transmitir. A Folha de Testemunho, documento em suporte papel, estará futuramente disponível na receção, onde os visitantes poderão deixar as histórias ou memórias associadas aos objetos. Esta informação será posteriormente tratada e utilizada para complementar a investigação sobre as coleções.

17 Assim sendo, é fundamental promover as exposições que despertem todos os sentidos, que cativem, que envolvam e que promovam uma participação proactiva do público. Só desta forma o Museu Nacional Ferroviário será de todos e para todos, local de transmissão de conhecimentos, fruto de vivências e histórias do passado, que permitem no presente contar o que já foi.

\section{BIBLIOGRAFIA}

Bruno, Maria Cristina Oliveira. 1997. "Museologia e Museus: Princípios, Problemas e Métodos." Cadernos de Sociomuseologia 10 (10).

MIDAS, 3 | 2014 
Câmara Municipal de Palmela. 2003. Memórias de Ferroviários de Pinhal Novo: Para a História da Vila e da Comunidade Ferroviária. Palmela: Divisão de Património Cultural, Câmara Municipal.

Chapouthier, Georges. 2006. “Registros Evolutivos.” Viver Mente \& Cérebro: Memória (2): 8-13.

Choay, Françoise. 1992. L'Allégorie du Patrimoine. Paris: Editions du Seuil.

Dias, Cláudia Cristian de Mesquita Garcia, Regina Abreu, e Mário de Souza Chagas. 2003. Memória e Patrimônio: Ensaios Contemporâneos. Rio de Janeiro: DP\&A Editora e FAPERJ: Uni-Rio.

Freitas, Silvane Aparecida de, e Maria Jacira da Costa. 2011. “A Identidade Social do Idoso: Memória e Cultura Popular.” Revista Conexão UEPG 7 (2): 202-211. http://www.revistas2.uepg.br/ index.php/conexao/article/view/3718.

Lei n.. 107/2001, de 8 de setembro, Diário da República, I série, ‥ 209 (2001).

Pesavento, Sandra Jatahy. 2002. “Memória, História e Cidade: Lugares no Tempo, Momentos no Espaço." Arte e Cultura 4 (4).

Quivy Raymond, e Luc van Campenhoudt. 2008. Manual de Investigação em Ciências Sociais. Lisboa: Gradiva.

Ribeiro, Raimundo Donato do Prado. 2003. "Memória e Contemporaneidade: As Tecnologias da Informação como Construção Histórica.” Última atualização a 10/03/2004. http:// www.comciencia.br/reportagens/memoria/13.shtml.

Santos, Maria Célia T. Moura. 2002. “Reflexões Museológicas: Caminhos de Vida.” Cadernos de Sociomuseologia 18 (18).

\section{NOTAS}

1. A fundação foi criada por iniciativa do Estado Português, da Câmara Municipal do Entroncamento, da empresa Comboios de Portugal (CP), da Rede Ferroviária Nacional (REFER), bem como de várias empresas privadas da área. O Engenheiro Ginestal Machado foi o grande responsável pela seleção e recolha de peças fundamentais para identificar a evolução da viaférrea, tendo constituído núcleos museológicos pelo país, num primeiro projeto do que viria a ser o Museu Nacional Ferroviário. Com efeito, trata-se de um museu com núcleos espalhados por todo o país (p. ex. Arco do Baúlhe, Bragança, Chaves, Estremoz, Lagos, Lousado, Macinhata do Vouga, Nine, Santarém e Valença).

2. Este projeto é cofinanciado pelo Programa Operacional do Centro (QREN), no âmbito das Parcerias para a Regeneração Urbana, sendo também apoiado pelo Instituto Turismo de Portugal ao abrigo do Programa de Intervenção do Turismo (PIT).

\section{RESUMOS}

Este pequeno texto tem como objetivo mostrar a importância da memória com recurso à recolha de testemunhos orais. Numa história que ainda tem muito por deslindar, recorrer ao saber de gentes que dedicaram a sua vida à ferrovia torna-se de extrema urgência, até pela finitude das 
fontes envolvidas. O projeto Entroncamento de histórias, levado a cabo pelo Museu Nacional Ferroviário, no Entroncamento, realiza-se há dois anos consecutivos e veio promover uma maior abertura à comunidade local, captando as narrativas daqueles que fazem parte da história dos caminhos de ferro. Assumindo a importância e o valor do património que é transmitido às gerações vindouras, estes testemunhos serão incorporados na futura exposição permanente do Museu Nacional Ferroviário de forma a complementar a informação sobre os objetos.

This short article demonstrates the importance of memory through collecting oral testimonies. In unraveling a story, the recovery of the knowledge of people who dedicated their lives to the Portuguese railroad system becomes of extreme urgency given the finitude of the sources involved. The project Entroncamento de histórias (meaning intersection of histories) carried out by the National Railway Museum, held for two consecutive years, has openned the museum to the local community, gathering the stories of those who made the history of the railways. As cultural heritage, to be transmitted to future generations, these testimonies will feature on the permanent exhibition at the National Railway Museum and will complement the objects.

\section{ÍNDICE}

Palavras-chave: memória, património cultural, Museu Nacional Ferroviário, história oral, património cultural imaterial

Keywords: memory, cultural heritage, National Railway Museum, oral history, intangible cultural heritage

\section{AUTOR}

\section{DANIELA RODRIGUES DO ROSÁRIO}

Licenciada em Comunicação Social, com especialização em Comunicação Empresarial (2009) pela Escola Superior de Tecnologia de Abrantes do Instituto Politécnico de Tomar (IPT) e pósgraduada em Ciências Documentais (2012) pela Escola Superior de Gestão de Tomar do mesmo instituto. No âmbito da pós-graduação realizou o projeto de investigação Comboio Foguete (195366): Da Construção da Narrativa à Exposição. É atualmente mestranda em Desenvolvimento de Produtos de Turismo Cultural no IPT e exerce funções como responsável pela comunicação e imagem do Museu Nacional Ferroviário. 